former gives nourishment to the body, and the latter exercises an alterative influence upon the process of tubercular change. Yet cod-liver oil should not be given by routine, but with definite rules as to its administration. To secure proper assimilation it should be prescribed in a teaspoonful dose at bedtime for three successive nights, then a dessert-spoonful at the same time. On the sixth and seventh days it should be taken in a dessert-spoonful dose after dinner and at bedtime, and afterwards in a tablespoonful dose after each meal. If so prescribed it does not cause eructation or nausea, and the doses may be increased in accordance with the wishes of the patient until the end of the fifth week, when it should be stopped for a week, and resumed. With each dose of the oil fivegrains of hypophosphite of lime dissolved in a little hot water should be taken. Thus administered, these medicines notably increase the strength of the patient, and returning health is evidenced by increased weight. If circumstances permit, and if the patient be young, a sea voyage is of inestimable advantage in maintaining the progress made to recovery, and if the voyage be to New Zealand and back in many cases the patient's health is established. I firmly believe that the hypophosphite of lime is the only form of hypophosphite of any value in tubercular disease. This opinion was expressed by me in communications to THE LANCET in 1876, when this salt was first introduced to the profession as an efficient therapeutic agent. All my subsequent experience confirms this view, and $I$ do not consider its influence is increased by its combination with the sodium and iron salts.

Chronic Constipation.

Most purgative medicines, if used for any length of time, require their doses to be increased, and the habit of employing them is engendered. Cascara sagrada, on the other hand, can be prescribed with advantage in diminishing doses, and in time can be omitted altogetber. Thus, a teaspoonful of the liquid extract, if given at bedtime, will cause action of the bowels after breakfast, which is accom. panied by no griping and no intestinal uneasiness. The next night the dose should be fifty minims, the next forty, the next thirty, the next twenty, and afterwards a tenminim dose should be taken for eight successive nights. As a rule it may then be discontinued, as the action of the bowels comes on in a natural manner at the same hour of the day.

Angina Pectoris.

In this affection there is little doubt of the benefit of the inhalation of the nitrite of amyl or of the taking of nitroglycerine-the latter being preferable for continued treatment. As illustrating this I shall give a short account of a case which came under my observation three years ago. I was called to see a man aged forty-five, whose condition was very pitiable. He was lying propped-up in bed, and complained of difficulty of breathing and intense cardiac pain. I prescribed a hydragogue cathartic, consisting of three grains of calomel and a quarter of a grain of podophyllin, and told him after the medicine had acted to take a tablet of nitro-glycerine twice daily. In the course of two days I saw him again, and found him much better. He has continued under my observation more or less since I saw him first, and can attend to his daily duties as a timekeeper in a large public work. The difficulty he experienced in walking with any ease has diminished by adopting a certain procedure in taking the tablets. His own words are: "There is a remarkable improvement in my health with regard to walking, and all through the tablets. By putting one in my mouth previously to starting to my work in the morning, I am able to walk at my ease to the gatehouse without halting. Previously to doing this I had to halt, until the pain ceased, from three to five times, and such has been the case for over two years; I can now walk the distance in less than five minutes, and I have known it to take metwenty. I can now walk from my house to the tram-car without a hall, when it usually took me from five to seven stops." Glasgow.

Munifichert GIFT.-Mr. E. A. Pearn of Compton Leigh, near Plymouth, has given a mansion and twenty. four acres of land for the benefit of the Royal Albert Hospital, Devonport, and the South Devon and East Cornwall Hospital, Plymouth. On the land he purposes to erect a convalescent home, and will endow it for the joint use of the two institutions named. The gifo has been gratefully accepted.

\section{DISEASE OF THE TEMPORAL BONE. ${ }^{1}$}

BY A. J. PEPPER, F.R.C.S. ENG., SURGEON TO ST. MARY'S HOSPITAL.

If I were asked to mention the surgical diseases in whick preventable deaths are most common I should cite strangulated hernia, perforation of the vermiform appendix, and suppuration in the mastoid cells. No doubt the majority of cases of inflammation of the middle ear and the surrounding bone tend to spontaneous cure, or at least to such amelioration as to place the sufferers apparently out of danger. I say apparently, because so long as a perforation of the tympanic membrane remains with discharge, how. ever slight, whether continuous or intermittent, there is an abiding cause of a possible fatal issue. How often do we meet with instances of ear disease in which, perhaps, years have intervened between the initial attack and the sub. sequent accession of acute symptoms $-a$ renewal of the storm with its attendant threatenings. But there is another reason for the delay or neglect, as the case may be, in resorting to early operative interference. I refer to the regional anatomy of the parts affected. The close juxtaposition of the brain, the lateral sinus, and the carotid artery to the area of primary mischief has undoubtedly led the practitioner too of ten to defer or abandon the only treatment likely to be of the least avail. I cannot too strongly. insist that such a reason implied or expressed is wholly untenable, that, in short, patients ought not to be left to a chance recovery when they can almost to a certainty be placed in security so far as life is concerned. The beneficial results oficered by operation are not confined to cases where the disease is limited to the middle ear and mastoid cells, for on several occasions consecutive abscess in the brain has been successfully treated.

As regards the causes of inflammation of the petro mastoid bone, it may be said that with few exceptions the affection is secondary to disease of the middle ear. Primary tubercular caries is comparatively rare, whilst syphilitic caries is much more so. Otitis media is usually the result of (1) some exanthematous fever, notably, scarlatina and measles; (2) disease of the naso-pharynx, such as ulceration and adenoid gowths (here the morbid change is due either to the inflammation spreading in the continuiby of the 'mucous membrane of the Eustachian tube, or to obstruction to the escape of secretion from the tympanum): (3) exposure to cold. I will not weary the reader with detailing the sequence of events, which ends in the petro-mastoid bone being involved, but at once proceed to discuss the latter condition, its feabures, phases, consequences, and appropriate treatment. According to Gruber the various parts of the temporal bone are attacked in the following order of frequency:-1. The mastoid cells. 2. The roof of the tympanic cavity. Here the principal danger to be feared is extension of the disease to the middle fossa of the skull, with meningitis and abscess of the temporosphenoidal lobe of the brain as natural consequences. 3. The posterior wall of the meatus. In this case an abscess may form between the bone and the external ear simulating true mastoid abscess. 4. The plate of bone separating the mastoid cells from the lateral sinus, in which thrombosis of the sinus and cerebellar abscess are events to be feared. 5. The floor of the tympanum and posterior wall of the carotid canal. Coagulation in the vein and hæmorrhage from the artery are possible sequelæ. 6. The petrous portion proper involving destruction of the labyrinth.

The above division is rather of pathological interest than clinical significance, for the disease is but seldom limited to the area first involved. I think it may be fairly said that few patients the subjects of chronic mastoid suppuration would lose their lives it the treatment were carried ont on rational surgical lines, for even in the worst cases-providing of course that intra-cranial mischief and pyæmia have not commenced-a wide opening and free excavation of the bone by relieving tension and affording a ready escape for discharge are rapidly and surely followed by marked relief from symptoms which disquiet the surgeon and distress the patient. As regards acute cases, where dangerous and too often fatal symptoms supervene closely on abscess formation in the middle ear, there is less time in which to act, for

1 A paper read at the Harveian Society, Feb. 18th, 1892. K 2 
blood poisoning and cerebral mischief are apt to ensue early and develop with great rapidity. Sir W. Dalby says that in this division must generally be placed the unavoidable deaths. Whilst agreeing in the main with his opinton, my own experience leads me to believe that here, too, the mortality is far higher than it should be. Let us take, for example, a case of suppurative inflammation of the middle ear accompanying, or following closely in the wake of, scarlet fever. The tympanic membrane bursts and affords an exit for the pent-up pus. There is a temporary lull in the symptoms, the pain lessens, and the temperature falls. Bub sonn the danger signals are full set again. What can the surgeon do more than use antiseptic injecbions, apply leeches, and carry out minor details which together make up the orthodox routine of treatment? If the mastoid cells are invaded, as they usually are, there is a resource left which ought at once to be employed-viz., to remove the outer plate of bone and break up the septal walls of the cells. I have practised this on several occasions, and always with complete success. There is no time to wait for fluctuation, œdema, or redness to manifest themselves externally, and there is no occasion for it. Deep.seated aching in the bone is always present; and, moreover, gentle percussion, and even pressure with the finger, suffices to increase the pain even when the superficial soft structures appear, and are in reality unaffected. I cannot lay too great stress on this fact. In cases like the above one has to meet the liability to suppuration in the skull, thrombosis of the lateral sinus, and pyæmia. The disintegration of septic clot in the sinus is a common canse of embolism and metastatic abscess. Thrombosis of the lateral sinus is indicated amongst other signs by odema and swelling of the side of the neck. Besides, the coagulation is apt to extend along the internal jugular vein, which can sometimes be felt as a solid cord. In such a state of affairs treatment offers libtle chance of success, but still it should not be abandoned in despair. Given a certain diagnosis of a septic thrombus in the sinus, I would not hesitate to lay it open. The liability to hæmorrhage, immediate and secondary, must be kept in mind. Even should such a disaster happen, it wonld not be difficult to arrest the bleeding. I have seen the patent sinus entered by a trephine and the patient recover. Touching intra-cranial suppuration, I may here note that abscess in the brain from middle-ear disease is found either in the cerebellum or the temporo-sphenoidal lobe of the cerebrum. It is more common in the former sibuation, except in very early life, when the reverse obtains. The reasons why cerebral absess is the rule in young children may be supplied, perhaps, by the following facts:1. The petro-mastoid and equamosal bones only undergo ossific union during the first year of life. Prior to this, suppuration may extend with readiness from the middle ear to the cranial cavity, the pus making its way through the thin intervening plate of cartilage. 2. The mastoid process is not formed until the second year, and the mastoid cells are not developed before the age of puberty. Although the mastoid bone contains in the first years of life a soft, jelly-like tissue which forms a favourable nidus for suppura. tion, the pus is not locked up, as it were, under pressure in bony cells. The least resistance is through the petrosquamosal suture and along the passage which transmits the large petrosal nerve. Relatively, too, I believe in very early life the plate of bone bounding the posterior fossa of the skull is thicker than that forming the roof of the ty $m$. panum.

I now proceed to discuss the principal complications of chronic disease of the petro-mastoid bone, and, first, I will treat of facial paralysis. From the long course the facial nerves take through the temporal bone extending from the internal anditory meatus to the stylo-mastoid foramen, and from the fact that there is sometimes a natural breach in the wall of the Fallopian aqueduct on its tympanic aspect, it is somewhat curious that it so often escapes being implicated. Facial paralysis from ear disease is relatively a rare event. It must al ways be considered a significant one, since we aee how readily the inflammatory process may extend along the nerve to the cranial cavity. Symmetrical paralysis from double ear disease $I$ have not seen. Now and then the nerve on the side opposite the bone lesion is affected. This may result from basic meningitis, but far more frequently it is part of a hemiplegia from abscess of the brain. Whether arising directly from the hone disease, or at a later stage from meningitis, the paralys is is as a rule general in its distribution, and not seldom total in quantity. On the other hand, when it participates in oue-sided palsy of the body, the murcles of the upper part of the face may be expected to retain their power, wholly or partially. The following case, whilso illustrating this point, may be looked upon as an epitome of neglected ear disease, consequent on naso-pharyngeal adenoid growths

W. $F$, aged nine, was admitted under my care into St. Mary's Hospital on A pril 14th, 1890. This is his history. From July, 1888, to 1889 he breathed with his mouth open. There was no deafness and no paralysis, and his sight was good. In October, 1889, he began to lose his sight, and shortly after a discharge was noticed from his left ear. In December, 1889, a lunup formed behind his left ear, which burst in January, 1890. A bout this time paralysis of the lower part of the right facial nerve and of the right arm manifested itself. Three months later the right leg was noticed to be weaker than the left. There had been no convulsions. In March, 1890, he was under the care of Dr. Bond, at the Golden-square Hospital. At that time there was offtnsive discharge from the left ear, and a sinus over the mastoid bone. He was almost absolutely blind. The pupils were large and equal; they acted but little to light. The ophthalmoscope revealed double optic atrophy. The right arm and leg were extensively paralysed. On April $2 n d, 1890$, Dr. Bond opened up the mastoid cells, and removed some post-nasal grow ths. On admission to St. Mary's, Mr. Juler reported double optic atrophy, with a small amount of central vision in the left eye. There was marked deafness in the left ear. The right upper limb was paralysed, mostly in the hand and forearm. The right leg was similarly affected. Both limbs were wasted and colder than on the left side. The urine contained no albumen and no sugar. On May $30 \mathrm{th}$, 1890 , with Dr. Broadbent's sanction, I trephined over the lefo temporo-sphenoidal lobe, and also over the cerebellum, but no abscess was found. Hernia cerebri formed at the former site. It was removed on Sept. 23rd, 1890, after which it re-formed to a less extent. The patient left the hospital unrelieveci on Jan. Ilth, 1891. A few months later he died, but unfortunately no necropsy was made. This case demonstrates inter alia how in. sidiously disease of the middle ear and temporal bone may progress. Commencing blindness was noticed about the same time as the aural mischief, the special symptoms of which were submerged, as it were, by the graver phenomena. There can, I think, be no doubt that had the mastoid bone been trephined early the lad might have escaped his subsequent troubles.

Deep suppuration in the neck may owe its origin to diseuse of the middle ear or mastoid bone. An abscess forming external to the mastoid process may of course burrow widely and deeply, bat I wish now to direct attention especially to a class of cases in which it com. mences at a greater depth. The local inflammation may extend either through the Glasserian fissure, in which event the temporo-maxillary articulation is very liable to suffer; or it may lead to perforation of the mastoid bone through the digastric fossa. Here the pus, meeting with the juxtaposed occipital artery, is conducted by it to the carotid sheath, along which it spreads. It is prevented from coming to the surface by the superjacent muscles and dense fascia.

J. K-, aged twenty-one, was admitted into St. Mary's Hospital on Sept. 22nd, 1890. He had had purulent dis. charge from the right ear as long as he could remember, but had suffered no inconvenience until a month before he came under my care. During that time he endured intense pain in the head. On admission his temperature was $105.8^{\circ} \mathrm{F}$, accompanied with rigors. There was a tense swelling beneath the right sterno-mastoid muscle. No tenderness over the mastoid bone or temporo-maxillary joint. An in cision an inch and a half long was made over the middle of the aterno-mastoid, and a large quantity of fetid pus evact ated. The abscess cavity reached from the base of the skull to the clavicle. His temperature next day was $97.5^{\circ} \mathrm{F}$. Two days later a subgluteal abscess formed, probably pyæmic in nature; this was opened and drained. The patient left the hospital well on Nov. 3rd.

Recurrent external mastoid abscesses, in consequence of insufficient opening and drainage, may form at long in. tervals, the patient meanwhile remaining exposed to more serious complications.

E. M-, aged fifteen, was admitted to St. Mary's Hospltal on July $16 \mathrm{th}, 1891$. Seven years previously an abscess 
formed over the left mastoid process; a second developed in the same situation twelve months since. Both healed completely, and, except for deafness and discharge from the ear, her health was good. Five weeks before admission suppuration again occurred. On the latter date pus was escaping from the meatus and also from a sinus over the bone. She was very deaf in the lefo ear. The posterior wall of the meatus was necrosed. I scooped out the mastoid, perforated the necrotic wall of the meatus, and passed a drainage-tube from the meatus to the opening made externally. She was discharged cured on Aug. 8th.

Necrosis of the posterior wall of the meatus has a special significance, inasmuch as the fungating granulations-sometimes described as polypi-forming around the dead piece of bone block up the paseage and hinder the escape of pas from the tympanum and mastoid antrum. Solong as the sequestrum remains, although the granulations may be completely removed, fresh ones spring up very rapidly, the patient thus obtaining only a brief respite from pain. Through the kindness of my colleague, Mr. Field, I assisted recently in removing a piece of loose bone from the ear of a lady, which had caused intense agony from the condition just referred to.

Implication of the temporo-maxillary joint is by no means infrequent in disease of the middle ear. It is usually associated with widespread affection of the mastoid. The inflammation extends through the Glasserian fissure or bebween the bone and the cartilage of the pinna. There is stiffness of the jaw, inability to open the mouth properly, and swelling over the head of the bune. Owing to the looseness of the articular capsule a quantity of fluid can be accommodated in the joint, and nence fluctuation is often obtained quite readily. It is of the greatest importance not to mistake an abscess working up by the side of the joint for synovitis of the latter. The former is diagnosed by the extreme throbbing pain and tenderness, and by the amount of swelling, which 18 more diffused than that from a distended capsule. Of course, inflammation of the joint may be purulent, in which case more or less permanent ixity is to be feared. If the synovitis has not passed beyond the stage of serous exudation, it mostly subsides very quickly after an adjacent abscess has been laid open. The tollowing case, for which I am also indebted to Mr. Field, shows the force of the foregoing remarks.

Mr. B- caught cold five months before he came under my notice, resulting in tympanic abscess, which perforated the drum. About four months later an abscess formed over the mastoid bone. This was opened, but the symptoms generally did not abate. At this time there were difficulty in moving the jaw and a painful swelling over the head of the bone. On laying open the sinus over the mastoid an orifice, just admitting a small probe, was discovered in the bone, from which pus was slowly escaping. I trephined and let out a quantity of matter which filled the antrum and smaller cells. Daring this procedure the mastoid vein was wounded-an accident of no great moment, - but the bleeding was readily stopped by plugging. Although considerable relief was at first experienced, the pain and swelling about the jaw in a short time became worse. I detected deep fluctuation just in front of the joint, made an ineision, and let out pus. A large portion of the zygoma was quite bared of periosteum; nevertheless, the patient made a rapid recovery, and the movement of the jaw became once moie painless and free.

Sclerosing ostutis of the mastoid bone from chronic ear iisease may prevent nature effecting an opening externally, and so increase the danger of suppuration spreading to the cranial cavity.

F. B-, aged about nineteen, deaf from childhood owing to disease of both middle ears. Latterly the pain in the left ear had been greatly aggravated. When seen in consultation with Mr. Field the pain over the mastoid was noticed to be much increased by pressure over the bone, althongh the sofo parts were quite healthy. The pupil on the same side was dilated and fixed. The thick oater plate of the mastoid was removed with the trephine and a drop or two of pus set free. The new bone, which had largely excroached on the antrum, was like ivory. A drain was inserted. A fortnight later, as the pain was not alleviated, further operation was resorted to. With a Marshall's osteotrite the cavity in the bone was enlarged, and deep in the interior another abscess, holding only a drop of pus, was enconntered. The pain soon afterwards ceased. The left pupil returned to i bs normal size. Noteworthy facts in this case are: 1. The temperature was raised but little above the normal. 2. That whereas in general the mastoid cells had been in great part obliterated by the new-bone formation, a tract of rarefying ostitis had absorbed the lay er next the lateral sinus, the wall of which could be felt and the pulsation of the brain seen to be communicated to fluid injected into the cavity made by the operation. It is next to certain that bad the patient been left to nature either thrombosis of the lateral sinus or cerebellar abscess would have ensued. M'Bride mentions sluggish pupils as a sign of intra-cranial irritation in chronic ear disease. In the case now narrated the pupil only on the affected side was dilated.

Wimpole-street, $\mathrm{w}$.

\section{SOME REMARKS ON DR. RUFFER'S LAST} PUBLICATION ON THE DESTRUCTION

\section{OF MICRO.ORGANISMS BY} AMOEBOID CELLS.

BY E. KLEIN, M.D., F.R.S.

IN THE LANCET of December 28th, 1891, there appears an abstract of a lecture delivered in the theatre of the Laboratories by my friend Dr. Ruffer, in which he criticises some remarks that I made in my lecture at the Royal Institution in February of last year concerning the insufficiency of Metchnikoff's theory of phagocy tosis to explain immunity. It is chiefly these criticisms of Dr. Ruffer about which I wish to make bere a few remarks.

On page $1433 \mathrm{Dr}$. Ruffer refers to a remark of mine as to the presence of phagocytes in the dorsal ly mph sac of the frog, being insofficient to explain the immunity of that animal against anthrax after the injection into the lymph sac of the anthrax virus. What I said is this: "It must seem very extraordinary that this--viz., the presence of phagocy tes-should be really a true explanation of the re. fractory state of the frog towards anthrax, considering that the bacilli, like other minute particles, when injected into the lymph sac would be absorbed and brought into the circulation in a few minutes, nay, seconds-at any rate some hours before the phagocy tes have got into the lymph sac in sufficient numbers to do battle with the bacilli." I have itulicised the word "sufficient," because, as will be seen presently, this is the essence of my remark, and it seems to have entirely escaped Dr. Ruffer's attention. Everyone. who has worked with anthrax in the frog knows that if intra. the dorsal lymph sac of this animal, while in the normal condition, a large dose of anthrax material, containing hundreds of thousands of anthrax spores or anthraxbacilli, be injected, no anthrax disease follows, and everybody who has read Ranvier's "Traité Technique d'Histologie " knows that the lymph of the dorsal lymph sac of the frog, like all lymph, contains amoboid leucocytes. The question of importance for the theory of phagocytosis is obviously one of numbers of lencocy tes present. Ranvier, who made this lymph the subject of special study, says (loc. cit., p. 149): "La quantité de ly mphe que ce sac eu contient est très variable suivant les circonsrances ; ainsi elle est en général presque nulle, si la grenonille a śéjourné longtemps dans un endroit sec." Frogs kept in the laboratory never contain more than a few drops of lymph in the lymph sac, and the number of lymph cells, though great in the microscopic specimen, is insignificant if compared with the enormous numbers of spores and bacilli that can be, and have been, injected into the lymph sac of such frog without producing anthrax. It is therefore quite unneces. sary for Dr. Ruffer to tell us that "he has found numerous phagocytes present in the normal lywph sac of the frogs he had examined." The point is not whether there are numerous leucocytes present in the Jymph sac-which nobody disputes, -nor whether some of these lencocytes contain the bacilli-which also nobody disputes, - bat the question is whether they are present in suffecient numbers to eat up and destroy the innumerable host of spores and bacilli injected, and whether the limited number of cells contaming the bacilli is at all in proporion to the work. Surely Dr. Ruffer does nut really maintain that spores and bacilli are not directly absorbed and carried into the circula. tion. He cannot mean to suggest that the number of cells containing the bacilli is at any time great, nor that the s xrplus of the spores and bacilli remain quietly lodged in 